\title{
Práticas Cotidianas de Letramento de Adolescentes
}

\author{
Acadêmicos do $5^{\circ}$ período de Letras (2009:1), Universidade Severino Sombra:
}

Allana Cristina Mesquita da Costa, Andréa da Costa, Claudilene Saldanha Araújo, Daniele Monteiro de Andrade, Fabiana de Fatima Serpa Fiochi, Fernanda Ferraz Barbosa, Hellem Darilo Ramalho, Juliana Sales Alves, Kátiússia de Deus da Costa, Patrícia Chagas Lisboa, Ronaldo Pereira de Aquino, Taíssa Vieira, Wânia da Silva Torquato, Wiliam de Carvalho Melo, Wilma Lucia Figueiredo de Araújo

\author{
Orientação: Rogéria Costa de Paula ${ }^{1}$ \\ ${ }^{1}$ Universidade Severino Sombra, Centro de letras, Ciências Sociais \\ Aplicadas e Humanas, Curso de Letras, rcostadepauladgmail.com
}

\section{Os estudos de letramento}

Esse trabalho tem como objetivo investigar quais são as práticas de letramento empregadas na vida cotidiana de adolescentes da região Sul-Fluminense e de uma localidade da baixada fluminense. Letramento deve ser aqui entendido como ações sociais desempenhadas por indivíduos mediadas pela escrita e, também, como construções sobre o mundo social e sobre si próprios que os sujeitos criam por meio da escrita. Como Barton (1994) afirmou, "há diferentes letramentos dos quais as pessoas se utilizam, associados com diferentes domínios da vida".

Barton \& Hamilton (2004) abordam o amplo conceito de letramento como sendo uma prática essencial em nosso cotidiano, pois é por meio dele que conseguimos localizarmo-nos entre o pensamento e o texto. Para eles, letramento é uma prática social, ou seja, é ação em que um dado indivíduo constrói sentidos do mundo social e de si próprio por meio da escrita. Assim, observa-se que não existem pessoas iletradas. Nessa perspectiva do letramento como prática social podemos afirmar como letrado é aquele que é capaz de fazer uso da escrita e da leitura no mundo social (cf. SOARES, 2000). Barton \& Hamilton (2004) compartilham dessa visão e esclarecem que existem pessoas que não são capazes de decodificar uma informação, mas que, na contemporaneidade, vivem em uma sociedade grafocêntrica, na qual os indivíduos são bombardeados por uma gama de textos escritos e por meio dos quais se localizam no mundo. Assim sendo, há pessoas que podem não decodificar textos redigidos em seu idioma, mas que, usualmente, se constituem no mundo social por meio da escrita.

Letramento, assim entendido, é uma prática plural, visto que há vários modos de ação que os indivíduos exercem a partir de suas interações com textos escritos. Em outras palavras, o letramento contemporâneo é constituído por intermédio de práticas dinâmicas, as quais sofrem mudanças segundo a série de informações a que se tem acesso.

Da mesma forma que os letramentos são plurais, as formas como as pessoas se engajam nessas práticas também variam. Segundo Barton \& Hamilton (2004), as pessoas podem se engajar em diferentes práticas de letramento, como, por exemplo, quando recebem

Mosaico - Revista Multidisciplinar de Humanidades, Vassouras, v. 1, n. 1, p. 60-67, jan./jun., 2010 
(Publicação de Textos, Ensaios e Artigos de Discentes) uma propaganda, quando lêem um anúncio, de sorte que o letramento não envolve somente práticas relacionadas a textos eruditos, mas também os textos do cotidiano.

\section{Letramento no cotidiano}

O fato de estarmos inseridos em uma sociedade grafocêntrica, em que a escrita está no centro das relações e interações sociais, impele-nos, como estudiosos da linguagem a refletir e pesquisar sobre os impactos da escrita em nossas vidas diárias. Como nossas rotinas são organizadas pela escrita? Em que medida nossas práticas comuns são moldadas por práticas de leitura e escrita? Essas são algumas questões básicas que podem ajudar-nos a compreender o papel da escrita em nossa vida cotidiana.

Barton e Padmore (1991) realizaram uma pesquisa com vinte pessoas para entender a influência e a significância da escrita em suas vidas e concluíram que a escrita é uma prática social que auxilia na manutenção da vida em família, da comunicação, ou ainda de questões pessoais. Segundo os autores "Muito da escrita que eles relataram consistiu da memória deles ou de mensagens para outros, ajudando-os a organizarem-se e organizarem suas casas" (Barton \& Padmore, 1991, p. 62).

Além disso, o trabalho indica que o grau de instrução das pessoas tem grande influência no desenvolvimento de sua escrita e de sua leitura e, ainda, influencia no desenvolvimento dos papéis sociais exercidos por cada indivíduo.

A análise de dados apresentada na pesquisa indica que a escrita interfere na vida familiar das pessoas, pois estas adquirem novos conhecimentos e vêem que são capazes de realizar diferentes atividades, conforme se inserem no mundo da escrita.

De acordo com Barton e Padmore (1991), há uma clara diferença entre homens e mulheres quanto à significância do papel exercido no gerenciamento da casa. As mulheres, na maior parte dos casos, cuidam da escrita de cartas, correspondências, listas de compras etc, enquanto os homens se responsabilizam pelo pagamento e administração de contas. Entretanto, estes papéis não são estáticos.

Cabe ressaltar que, apesar da importância da escrita, há muitas pessoas que possuem deficiência no que tange a essa prática, seja por dificuldade de expressão ou até mesmo por erros ortográficos, ocasionando a preferência dessas pessoas pela leitura ao invés da escrita para agir socialmente. Entretanto, é difícil classificar de modo generalizado as preferências, pois cada pessoa tem suas próprias práticas e um jeito único de ser e agir no mundo social por meio da escrita.

Assim, não se pode determinar padrões envolvendo classificações dos usos da escrita que os indivíduos fazem. Segundo Signorini (1995), a determinação de padrões contribui para o preconceito lingüístico, para a desqualificação do falante e de seu desempenho. Para a autora, a distinção: letrado - não letrado, ou: escolarizado analfabeto, coloca em jogo a projeção de uma linguagem comum entre cidadãos que se contrapõe entre os que manobram e os que são manobrados, entre os que queremsabem-podem falar e os que se calam ou só fazem ruídos. 


\section{Letramento e Identidade}

(Publicação de Textos, Ensaios e Artigos de Discentes)

Magalhães (1995) aborda o letramento relacionado à construção da identidade feminina a partir da perspectiva de uma comunidade periférica de Brasília, onde metade da população é considerada analfabeta.

Segundo a autora, dentro deste grupo de não-alfabetizados encontra-se um número considerável de mulheres que foram vítimas de uma cultura em que os homens eram enviados às escolas, enquanto as mulheres "de família" permaneciam em suas casas a fim de auxiliarem no trabalho doméstico. Assim, este panorama permite-nos refletir a respeito do conceito de práticas discursivas e de letramento, que se dão em meio às práticas sociais que possibilitam múltiplas produções discursivas.

Street (1993, p. 12-13) apud Magalhães (1995, p. 204) assinala que “... práticas de letramento incorporam não apenas 'eventos de letramento', ocasiões empíricas integradas pela escrita, como também 'modelos populares' destes eventos e as preocupações ideológicas que lhes são subjacentes". Ou seja, práticas de letramento não envolvem somente a escrita, mas também, as relações dialógicas necessárias à produção e interpretação discursiva que serve como pano de fundo desse processo. Isso se confirma nas palavras de Magalhães (1995, p. 205): "As práticas discursivas e letramento são matrizes históricas que determinam a produção e a interpretação de instâncias concretas e textos falados ou escritos, com emissores e receptores concretos, construindo identidades, valores e crenças mediadas pelo meio escrito". Percebemos assim que o meio escrito não é o ponto central desta questão, mas sim apenas um entre outros possíveis de serem utilizados.

Um aspecto do trabalho de Magalhães (1995) é a questão da interpretação, visto que discute a relação da comunidade, com considerável taxa de analfabetismo, e a escrita. $\mathrm{Na}$ visão da autora, "o fato de metade da população da vila não ser alfabetizada determina os usos da escrita nos letreiros e placas nas ruas do Paranoá [bairro investigado]. Nesse sentido, toda a produção escrita é adaptada de maneira que possa atender às necessidades da população a que esta sendo direcionada. Desta maneira, “... os letreiros apresentam cores fortes, que são interpretadas pela população nãoalfabetizada". Pode-se se inferir que a interpretação tem ali uma relação com as propriedades do texto e os recursos utilizados pela comunidade a fim de buscar um sentido para ele.

Tomando o texto como o produto de um processo que não necessariamente utiliza palavras, entendemos onde habita a capacidade de interpretação desses indivíduos que têm suas práticas de letramento deslocadas do campo da escrita para o campo da interpretação com a utilização dos fatos cotidianos, podendo concluir que este ato está, em certa medida, intimamente relacionado a tais práticas.

Neste tocante, entendemos que as identidades sociais podem ser compreendidas nas práticas discursivas e consideramos o discurso como prática social. Entender o discurso dessa forma implica três questões, segundo Fairclough (1992, p. 63-64).

Primeiro, o discurso é um modo de ação sobre o mundo e sobre os outros. É também um modo de representação da realidade. Desse modo, a linguagem é uma ação lingüística realizada individualmente. Porém, deve-se levar em consideração os "atos de fala", os quais correspondem ao que pode e deve ser dito em uma determinada prática discursiva.

Mosaico - Revista Multidisciplinar de Humanidades, Vassouras, v. 1, n. 1, p. 60-67, jan./jun., 2010 
(Publicação de Textos, Ensaios e Artigos de Discentes)

Segundo, o discurso se relaciona com a estrutura social, ou seja, é moldado pela estrutura social, pelas relações de classe social, gênero e etnia, bem como, nos níveis institucionais e situacionais, por normas e convenções discursivas e não-discursivas. Esses eventos discursivos podem ocorrer de acordo com a instituição, como o direito, a educação, a mídia ou outro domínio social específico.

Na terceira implicação, o discurso contribui para construir:

todas as dimensões da estrutura social que direta ou indiretamente o moldam e restringem: as próprias normas e convenções, como também as relações, identidades e instituições que estão por trás delas. O discurso é uma prática não apenas de representação do mundo, mas de significação do mundo, constituindo e construindo o significado do mundo (Fairclough, 1992, p. 6364 apud Magalhães, 1995 pp. 213-214).

Sendo assim, o sujeito agente em uma prática discursiva passa a ser constituído por um sistema de relações em que o espaço institucional, os códigos de percepção, suas observações e informações já adquiridas, façam com que esse sujeito exerça múltiplos papéis no espaço social em que vive, realizando uma prática discursiva.

Adotando um outro viés, Giddens (1991 apud Magalhães, 1995, p. 215) desenvolve uma reflexão sobre o conceito de identidade na sociedade contemporânea, baseando-se em três fatores, a saber: a separação de tempo e espaço, os mecanismos descontextualizados e a reflexividade institucional. A separação de tempo e espaço consiste na condição para a articulação de relações sociais, os mecanismos descontextualizados separam a interação das particularidades dos locais, sendo realizado por sistemas abstratos e, a reflexividade institucional que consiste no uso regularizado do conhecimento sobre a circunstância da vida social, como um elemento construtivo em sua organização e transformação.

Após pontuar a visão desses dois pesquisadores, compreendemos que a língua escrita permite a leitura de quaisquer textos, ainda que tenham sido produzidos em épocas e locais particulares. Para Foucault (1987), uma prática discursiva de letramento ocorre mediante um sistema de relações, não havendo como descontextualizar a escrita e nem os sistemas globais (televisão, computador) da prática social. Contudo, é nessa prática que se constrói a separação entre as interações sociais e os contextos de produção textuais. Além disso, é importante destacar que a língua escrita contribui para a formação da identidade por meio da reflexividade institucional,e assim, de maneira distinta, a identidade das pessoas que apenas falam a língua e das pessoas que falam e escrevem a prática discursiva pode ser construída, porque uma pessoa que não domina a escrita pode obter um conhecimento amplo no que se diz respeito a valores e crenças na língua falada.

\section{Contexto metodologia de pesquisa}

O presente trabalho trata de um projeto piloto desenvolvido pelos alunos do $5 .^{\circ}$ período de Letras, $1^{\circ}$ semestre/2009, da Universidade Severino Sombra (USS), no tocante à disciplina Linguística Aplicada ao Ensino e organizada pelo Centro de Estudos Linguísticos e Sociais (CELES/USS).

O trabalho segue uma perspectiva social da linguagem, em que os indivíduos atuam discursivamente, para agir no mundo social, enquanto se posicionam reflexivamente

Mosaico - Revista Multidisciplinar de Humanidades, Vassouras, v. 1, n. 1, p. 60-67, jan./jun., 2010 
(Publicação de Textos, Ensaios e Artigos de Discentes) (Van Langenhove \& Harré, 1999) em relação uns aos outros. Com o intuito de construir inteligibilidades a respeito das construções sociais de adolescentes e jovens das regiões citadas, como agentes discursivos em uma sociedade grafocêntrica, esse trabalho adota o instrumento metodológico do questionário para levantamento de informações sobre as práticas de escrita e de leitura dos participantes.

Para tanto, os alunos do $5 .^{\circ}$ período de letras formularam um questionário com um total de 26 questões. Especificamente, os questionários foram aplicados a adolescentes e jovens moradores de diversas cidades da região sulfluminense e de uma cidade da baixada fluminense, a saber, Barra Mansa, Mendes, Miguel Pereira, Paty do Alferes, Paracambi, Paulo de Frontin, Três Rios, Valença e Vassouras.

Os questionários foram analisados segundo uma visão qualitativa e interpretativista ${ }^{\mathrm{i}}$, uma vez que o pesquisador coloca o foco nas interpretações das categorias mais recorrentes nos dados gerados.

\section{Perfil dos participantes}

A pesquisa contou com a participação de 31 adolescentes e jovens, sendo 18 do sexo masculino e 13 do sexo feminino, moradores da região sulfluminense e de uma cidade da baixada fluminense. São estudantes de escolas particulares e públicas, matriculados em turmas de ensino fundamental e médio e em turmas de Educação de Jovens e Adultos (EJA).

Também participam os alunos do então $5^{\circ}$ período de Letras, sendo 13 mulheres e dois homens, moradores das cidades citadas. Muitos são professores dos adolescentes e jovens participantes.

\section{Análise de dados}

O principal objetivo dessa análise é conhecer o lugar social ocupado pela escrita na vida dos participantes e interpretar os modos como os adolescentes participantes se autoposicionam, socialmente, quando o foco é colocado na prática da leitura e da escrita.

Para realizar a discussão dos dados abaixo, selecionamos algumas questões do questionário que julgamos serem as mais relevantes para responder as questões motivadoras desse trabalho, a saber:

Quais as demandas da escrita na vida cotidiana de adolescentes da região sulfluminense?

O que os adolescentes da região sulfluminense estão lendo?

Os relacionamentos com a leitura e a escrita dos adolescentes participantes do trabalho correspondem às demandas da vida contemporânea em que a sociedade é denominada grafocêntrica?

Ao responder tais questões, os dados parecem indicar que a escrita, para esses adolescentes, ainda, está bastante ligada às atividades escolares. Em outras palavras, observa-se que os participantes não teriam percebido a função social da escrita em seus cotidianos. Em contrapartida, os dados apontam que eles reconhecem a importância da escrita no universo virtual da internet (e-mails, MSN, orkut, etc.). Dessa forma, no 
(Publicação de Textos, Ensaios e Artigos de Discentes) nosso modo de entender, os adolescentes representam a escola como uma instituição social que continua ocupando o lugar de principal motivação para práticas de letramento, ainda que vivamos em uma sociedade em que a linguagem escrita é difundida de diversas maneiras, constituindo o centro da vida social.

Quando perguntados sobre o que costumam ler, as respostas dos adolescentes apontam para os seguintes resultados: 11 alunos preferem jornal e, inclusive, fizeram referência à coluna de esportes, 10 preferem revistas, 5 opinaram por livros e outros 5 por email/internet. O que esses dados parecem dizer é que, talvez, haja maior acessibilidade a jornais e revistas, no que diz respeito a textos impressos. Além disso, cabe ressaltar que a linguagem dos jornais e revistas é de mais fácil compreensão do que a de um texto literário, por exemplo. Além de focalizarem fatos do dia a dia das pessoas, leva os leitores a terem maior interesse pelo que está veiculado devido, às possibilidades de identificação com a sua própria história.

Em relação ao fato de, no total de 31 questionários respondidos, em apenas 5 foi marcada a preferência pela leitura de livros, acredita-se que essa escolha seja modelada por questões financeiras, visto que os jornais populares custam de cinquenta centavos a um real e cinquenta centavos, havendo revistas populares de um ou dois reais, enquanto que os livros custam em torno de 30 reais, sendo de dez reais os mais baratos encontrados no mercado.

Também o fato de 5 respostas indicarem a preferência por internet pode ser explicada pelo fato do acesso que, muitas vezes, se dá nas escolas, visto que são poucos os jovens que têm acesso à internet em casa.

Assim, talvez, no que tange à leitura dos adolescentes entrevistados, possa-se avaliar que lêem textos com cujas histórias se identificam, ou que têm acesso e/ou, ainda, aquilo que lhes satisfaçam os interesses e curiosidades.

No tocante aos objetivos por que lêem, as respostas dos adolescentes demonstram que eles se preocupam em buscar conhecimentos. Isso pode ser uma influência da sociedade contemporânea, que nos bombardeia com uma gama de informações, veiculadas por meio de diferentes tecnologias. Em outras palavras, os adolescentes, na era da informação, podem estar se sentindo desafiados a buscar novas maneiras de se atualizarem. Quando foram perguntados sobre a leitura predileta, indicaram que buscam diversão e que a encontram em revistas "teens" e em sites de relacionamentos (orkut, MSN, etc.). Informaram que buscam também o que está na "moda" além de autoconhecimento, quando lêem o horóscopo.

\section{Considerações finais}

Este trabalho investigou os usos da escrita de adolescentes moradores da região sulfluminense e de um município da baixada fluminense, por meio de questionário para categorizar as situações em que empregam a escrita, bem como para conhecer os principais gêneros lidos nos seus cotidianos.

Os dados gerados pelos participantes apresentam uma multiplicidade de gêneros que interessam. Alguns coincidem com aqueles tradicionalmente legitimados na esfera escolar, enquanto outros revelam uma compatibilidade com as demandas da sociedade moderna, pois demonstraram interesse por textos da internet e por práticas de escrita em 
(Publicação de Textos, Ensaios e Artigos de Discentes) circunstâncias em que as tecnologias são elementos de mediação, em lugar dos textos literários, narrações, dissertações, que são preferidos pelas escolas.

Dessa forma, acreditamos que esse trabalho coloca a escola diante do desafio de buscar compreender as práticas cotidianas de letramento, ressignificá-las. Assim, trazemos à baila as principais questões que a escola, a nosso ver, deve buscar responder:

- Quais os objetivos dos adolescentes da região sulfluminense e de um município da baixada fluminense, quando buscam textos ou sites da Internet?

- De que forma as tecnologias organizam os textos? Como as categorias desses textos podem ser empregadas nos letramentos escolares para que os alunos ali situados possam ler com objetivos que lhes interessam?

Somente depois de respondidas tais questões é que a escola poderá buscar formas de sensibilizar os alunos para que tomem os objetivos escolares como válidos para suas vidas.

Um aspecto relevante nos dados obtidos é o de ser, para os participantes desse trabalho, o letramento tomado como uma prática escolar. Esse modo de entender letramento é problemático, se tomarmos como ponto de partida o que vem sendo defendido pelo The New London Group (2005), que afirma ser a sociedade contemporânea grafocêntrica. Assim, se os adolescentes e jovens lêem tão-somente no espaço escolar, possivelmente eles enfrentarão dificuldades para resolver questões de uso de escrita, quando se inserirem em outras instituições sociais, as quais têm seus letramentos peculiares e seus modos próprios de significar a escrita.

\section{Notas}

1 "Dentro do paradigma interpretativista, o fato social não pode ser analisado objetivamente, porque ele não é um fato único, ele não se esgota em si mesmo, mas é fruto de outros fatos sociais e desse modo, entendemos que não há como controlar as variáveis em contextos humanos, ou seja, não há como organizar a realidade social" (cf. Nunan, 1992 apud Costa de Paula, 2002, P. 81).

\section{Referências Bibliográficas}

Barton, D. (1994). Literacy: An introduction to the ecology of written language. Oxford: Blackwell.

Barton, D. \& Hamilton, M. La literacidad entendida como práctica social. In.: Zavala V.; Niño-Murcia M. \& Ames, P. (ed.) (2004). Escritura y sociedad. Nuevas perspectivas teóricas y etnográficas. Red para el Desarrollo de las Ciencias sociales en el Perú, pp. 109-139.

Barton, D. \& Ivanic, R. (1991). Writing in the community. London: Sage Publications, pp. 58-77.

Barton, D. \& Padmore, S. (2002). Roles, networks, and values in every day writing. In: Costa de Paula, R. Leitura como prática social na escola: a construção das 
Práticas Cotidianas de Letramento de Adolescentes

(Publicação de Textos, Ensaios e Artigos de Discentes) negritudes e das masculinidades. Rio de Janeiro, UFRJ, Faculdade de Letras. Dissertação de Mestrado no Programa Interdisciplinar de Linguística Aplicada.

Fairclough, N. (1992). Discourse and social change. Cambridge: Polity Press.

Foucault, M. (1987). A arqueologia do saber. Trad. Luiz Felipe Baeta Neves. Rio de Janeiro: Forense-Universitária.

Giddens, A. (1991). Modernity and self-identity: Self and Society in the Later Modern Age. Cambridge, Polite Press.

Magalhães, I. (1995). Práticas discursivas de letramento: a construção da identidade em relatos de mulheres. In: Kleiman, A. B. (org.) Os significados do letramento. Campinas: Mercado de Letras.

Nunan, D. (1992). Research Methods in language learning. Cambridge: Cambridge University Press.

Signorini, I. (1995). Letramento e (in) flexibilidade comunicativa. In: Kleiman, A. B. (org.) Os significados do letramento. Campinas: Mercado de Letras.

Soares, M. (2000). Letramento. Um tema em três gêneros. Belo Horizonte: Autêntica.

Street, B. (1984). Introduction: "The New Literacy studies". In: Street, B. (org) CrossCultural Approaches to Literacy. Cambridge: Cambridge University Press.

The New London Group. (2005) A pedagogy of multiliteracies designing social futures. In: Cope, B. \& Malantzis, M. (ed.) Multiliteracies. Literacy learning and the design of social futures. New York: Routledge, [2000] 2005.

Van Langenhove, L. \& Harré, R. (1999). Introducting positionin theory. In: Harré, R. \& Van Langenhove, L. (eds) Positioning theory. Oxford: Blackwell. 